\title{
Acute lower gastrointestinal bleeding: Part 1
}

\author{
Robert Enns MD FRCPC
}

\begin{abstract}
R Enns. Acute lower gastrointestinal bleeding: Part 1. Can J Gastroenterol 2001;15(8):509-516. Acute lower gastrointestinal (LGI) bleeding is typically caused by vascular malformations, diverticuli and neoplasia. Although endoscopic evaluation of the colon is relatively standard in stable patients with LGI bleeding, those with significant ongoing hemorrhage are often more difficult to evaluate endoscopically. Other investigative techniques such as nuclear scintigraphy, angiography and surgical exploration have been commonly used in unstable patients with LGI bleeding when the exact site is unknown. These investigative techniques have had variable measures of success. This two-part review evaluates the literature in an attempt to review the optimal investigative approach in patients with LGI hemorrhage, in particular patients who have had significant and ongoing bleeding. Part 1 of this article concentrates on the etiology of LGI hemorrhage, followed in a subsequent article by diagnostic and management strategies. Following the review, a consensus update will be included with guidelines for clinical use.
\end{abstract}

Key Words: Diverticuli; Lower gastrointestinal bleeding; Neoplasia; Vascular malformations

\section{Hémorragie digestive basse aiguë : $1^{\text {re }}$ partie}

RÉSUMÉ : Les hémorragies digestives basses (HDB) aiguës sont généralement causées par des malformations vasculaires, des diverticules ou des lésions néoplasiques. Même si l'examen endoscopique du côlon est relativement fréquent chez les patients stables présentant des HDB, il en va autrement pour les patients souffrant d'hémorragies importantes continues dont l'état est souvent plus difficile à évaluer par endoscopie. Les médecins ont souvent recours, avec plus ou moins de succès, à d'autres techniques d'exploration comme la scintigraphie, l'angiographie ou la chirurgie dans les cas où le siège exact de l'hémorragie est inconnu. Le présent article, divisé en deux parties, passe en revue la documentation scientifique sur l'approche exploratoire optimale à adopter chez les patients atteints d'HDB, notamment chez ceux dont les saignements sont assez importants et continus. La première partie traite surtout de l'étiologie des $\mathrm{HDB}$, et la deuxième, de stratégies diagnostiques et thérapeutiques. Suit une mise à jour consensuelle comportant des lignes de conduite à visée clinique.

\begin{abstract}
A lthough endoscopic therapy has proved to be efficacious in the management of upper gastrointestinal (UGI) bleeding, its role in acute lower gastrointestinal (LGI) bleeding continues to be controversial. There are numerous reasons for the controversy. Most published data evaluating LGI bleeding are derived from case series completed in tertiary-care centres that combine patients with
\end{abstract}

mild, moderate and severe LGI bleeding. This limits the applicability of these findings to smaller centres and individual patients because these data may not apply to regions where endoscopists are not routinely exposed to acute LGI bleeding. In addition, management protocols clearly should vary depending on the severity of bleeding. Colonoscopic examinations in severe, acute LGI bleeding may be difficult

Division of Gastroenterology, Department of Medicine, St Paul's Hospital, Vancouver, British Columbia

Correspondence: Dr Robert Enns, Division of Gastroenterology, Department of Medicine, St Paul's Hospital, \#300-1144 Burrard Street,

Vancouver, British Columbia V6K 2A5. Telephone 604-688-7017, fax 604-688-2004, email renns@interchange.ubc.ca

Received for publication October 1, 1999. Accepted November 15, 1999 
TABLE 1

Differential diagnosis of lower gastrointestinal hemorrhage

\begin{tabular}{lc}
\hline Diagnosis & Incidence (\%) \\
\hline Diverticular disease & 40 \\
Inflammatory bowel disease & 21 \\
Neoplasms & 14 \\
Coagulopathy & 12 \\
Anorectal disease & 11 \\
Arteriovenous malformation & 2 \\
Radiation proctitis/enteritis & $<1$ \\
Intussusception & $<1$ \\
Endometriosis & $<1$ \\
Small intestinal sources & \\
$\quad$ Arteriovenous malformations & N/A \\
Diverticula & Vasculitis \\
\hline
\end{tabular}

Data from reference 22. N/A Not Available

to perform due to blood that obscures the mucosa as it refluxes throughout the colon, even if it originates from a distal site. Alternatives for diagnosis and therapy include radiological and surgical interventions, which are often used for acute, severe hemorrhage but carry considerable morbidity and mortality $(1,2)$. Despite numerous advances in diagnostic strategies over the past several decades, as many as $8 \%$ to $12 \%$ of patients with acute, severe LGI bleeding still undergo surgery without localization of the bleeding site. Up to $33 \%$ of patients continue to bleed postoperatively (3-5). Furthermore, LGI bleeding tends to be intermittent, with $85 \%$ of patients undergoing spontaneous cessation $(6,7)$; this creates difficulty in assessing clinical outcomes because the majority of patients stop bleeding regardless of therapeutic intervention. Finally, ready access to emergency colonoscopy is not universal, and with evertighter financial constraints, endoscopy units are under increased pressure to meet budgetary demands by restricting the number of endoscopic procedures. This pressure may encourage some gastroenterologists (who would otherwise use emergency endoscopy) to opt instead for an alternative mode of investigation and management.

Although consensus guidelines (8), and recommendations for investigation and management of LGI bleeding exist (3,9-14), there is no universally accepted method that applies to all patients. The present article offers a review of the published literature in an effort to assist endoscopists with their management of patients with LGI bleeding, with an emphasis on assessment and treatment of massive LGI bleeding, and to develop further practice guidelines for management.

The most important initial step in assessing a patient with LGI bleeding is the history and physical examination. Clearly, the accurate, expedient assessment of the airway, breathing and circulation guides the speed at which resuscitation is initiated. At times, the clinical presentation of UGI bleeding can be identical to that of LGI bleeding; therefore, use of nonsteroidal anti-inflammatory drugs, or a history of peptic ulcer disease, dyspepsia or liver disease may dramatically change the sequence of investigations. Similarly, a change of bowel habits, anorectal complaints or a history of hematochezia can alter the course of investigations if noted. The assessment of hemodynamic stability and the estimation of the amount of blood loss are the next steps. Adequate intravenous access of crystalloid and colloid should be administered to all patients with suspected moderate or massive gastrointestinal bleeding. If there is any suspicion of UGI bleeding resulting in hematochezia, insertion of a nasogastric tube or even an upper endoscopy may be warranted to identify the bleeding site. In certain instances, proctoscopic examination is indicated for the assessment and subsequent treatment of hemorrhoids, which occasionally can present with severe bleeding.

\section{CLINICAL PRESENTATION OF LGI BLEEDING}

The timing and type of gastrointestinal investigations depend primarily on the type of LGI bleeding.

There are three clinical presentations of LGI bleeding to consider, as follow:

- Hemoccult (Beckman Coulter Inc, USA)-positive stools, found as part of an outpatient investigation or screening examination. These patients tend to have chronic blood loss, which can be investigated on an outpatient basis. Sometimes both UGI and LGI tract investigations are required to clarify the source of bleeding, because positivity on Hemoccult may result from bleeding either proximal or distal to the ligament of Treitz.

- Passage of minimal amounts of bright red blood per rectum. This problem can often be clarified by an appropriate history and a careful perianal examination. Typically, the cause is an anal fissure, hemorrhoids or other distal colonic lesions. Proctoscopy combined with flexible or rigid sigmoidoscopy, in most cases on an elective basis, is usually sufficient to diagnose the problem.

- Massive LGI blood loss. Hematochezia is a term derived from the Greek haimatos, meaning 'blood' and chezein meaning 'to go to stool' (15). Massive LGI blood loss is arbitrarily defined as bleeding below the ligament of Treitz that is severe enough to require blood transfusions of 3 to $5 \mathrm{U}$ to maintain hemodynamic stability. This definition is somewhat controversial because different studies have used different criteria. Other definitions include hematocrit under $30 \%$, any orthostatic changes in blood pressure and a requirement for any quantity of transfused blood associated with the passage of bright red blood per rectum (16).

\section{ETIOLOGY}

Massive hematochezia typically occurs in elderly patients (average 60 years of age) (17). It carries a mortality rate of up to $30 \%(7,18-20)$ and accounts for about $0.7 \%$ of all dis- 
TABLE 2

Common causes of massive lower gastrointestinal bleeding by age

Adolescents and young adults (aged 13 to 40 years)

Meckel's diverticulum

Inflammatory bowel disease

Polyps

Adults younger than 60 years of age

Diverticula

Inflammatory bowel disease

Neoplasms

Adults older than 60 years of age

Angiodysplasia

Diverticula

Neoplasms

Data from reference 23

charges from hospital. This illness is, therefore, significant and costly (21). Although there are many possible causes of LGI bleeding (Table 1) (22), the etiology of massive LGI bleeding is much more limited. Massive LGI bleeding can be classified by age-specific diagnosis (Table 2) (23) or by incidence (Table 3) (24). Most evaluations of massive LGI bleeding are single-centre studies based on relatively small numbers of cases; the data often reflect referral, diagnostic and treatment biases existing at local institutions. Nonetheless, when the data of several studies are combined, the results suggest that the most common cause of massive LGI bleeding is likely diverticulosis, which accounts for approximately $30 \%$ to $40 \%$ of all cases $(4,22,24-28)$. Although arteriovenous malformations account for only $2 \%$ of all LGI bleeding (22), they account for $15 \%$ to $30 \%$ of massive gastrointestinal hemorrhage (3,24-33). Other causes of massive LGI bleeding include (in order of decreasing frequency) cancer, polyps, inflammatory bowel disease and ischemia.

\section{SPECIFIC CAUSES OF LGI BLEEDING}

Colonic diverticulosis: Colonic diverticula are defined as false, pulsion diverticula because they consist of mucosa and serosa. Although more than 50\% (34) of all people over age 60 years have radiological evidence of diverticula, only $20 \%$ (35) experience bleeding. Of these people, $80 \%$ will stop bleeding spontaneously, 35\% will require transfusion or invasive diagnostic/therapeutic intervention and 5\% will have massive hemorrhage and ultimately require an emergency operation $(5,35-39)$. Diverticula are believed to originate when increased luminal pressure causes a segment of the mucosa to extrude through weaker areas of the muscularis mucosa. The muscularis mucosa tends to be weaker in sites where there are penetrating arterial vasa recta. Meyers et al (40) postulated that injurious factors arising within the colonic or diverticular lumen damage the luminal side of the underlying vas rectum, resulting in weakening of the

TABLE 3

Differential diagnosis of lower gastrointestinal bleeding

\begin{tabular}{ll}
\hline Common & Uncommon \\
\hline Diverticula & Inflammatory bowel disease \\
Vascular ectasia & Infectious colitis \\
Neoplasia (polyps/cancer) & Radiation colitis \\
Perianal bleeding (hemorrhoids) & Rectal varices \\
& Rectal ulcers \\
\hline
\end{tabular}

arterial wall at this site. This theory is supported by histopathological lesions seen in the vasa recta such as intimal thickening, duplication of the internal elastic lamina and thinning of the media.

Bleeding associated with diverticulitis tends to be mild and stems from mucosal inflammation in the region of the inflamed diverticulum (40). Conversely, bleeding from diverticulosis tends to be sudden and significant because it originates from an arterial source. If bleeding is recurrent and mild, one should ensure that other sources of bleeding, such as polyps and cancer, have been excluded. As noted above, most diverticular bleeding ceases spontaneously. Unfortunately, $25 \%$ of patients who have diverticular bleeding experience a second episode, and of these patients, more than $50 \%$ will bleed again if definitive therapy is not initiated $(3,5)$.

Although most diverticula are located distal to the splenic flexure, $60 \%$ of those found to be bleeding at mesenteric angiography are located proximal to the splenic flexure (23). It is often mistakenly stated and believed that the bleeding is from diverticula (ie, multiple sites), when a single diverticulum is usually responsible for the bleeding, regardless of the number of diverticula. It is unclear why bleeding appears to be more common from right-sided than from left-sided colonic diverticula.

Treatment for recurrent bleeding (usually after the second mild to moderate episode) or for persistent bleeding from a diverticular source is traditionally surgical. Diagnostic studies are required to identify the site of colonic bleeding in an effort to guide the surgical resection. Endoscopic therapy can help identify the site in some patients and, in a select group, treat the bleeding. Although endoscopic electrocoagulation of a thin-walled diverticulum has been considered to carry a high risk, a recent small series reported success in three patients without complication $(41,42)$. These patients had had recurrent bleeding from a diverticulum and were found to have a visible vessel at the edge of a diverticulum. They were treated with gold probe electrocautery, using a $50 \mathrm{~W}$ generator with a power setting of $20 \mathrm{~W}$. The patients were managed on bulk agents and followed for a median of three years, with no evidence of rebleeding.

Other endoscopic options include target suctioning (43) and selective adrenaline injection into the base and sides of the diverticulum (44). Induced vasoconstriction, in addi- 
tion to mechanical tamponade, likely contributes to successful endoscopic outcomes (33). Other techniques, such as the use of hemoclips, occasionally have been reported to be successful $(45,46)$. More recently, endoscopic band ligation has even been successfully performed in a small number of patients with bleeding diverticuli (47). No controlled trials have been performed to assess critically these innovative techniques.

Arteriovenous malformations: Arteriovenous malformations (AVMs) are also known as angiomas, angiodysplasias and vascular ectasias. They were first noted to be responsible for gastrointestinal hemorrhage in 1960, when Margulis et al (48), using operative mesenteric arteriography, discovered the presence of these vascular bleeding lesions. Since that time, the use of angiography $(17,49)$ and colonoscopy $(17,48-54)$ has identified them as a significant cause of gastrointestinal hemorrhage.

AVMs are seen most commonly in the right colon and cecum (3), and occur with increasing frequency with advancing age. Although the mean age of symptomatic patients is 70 years, $2 \%$ to $30 \%$ of the population older than 50 years harbour these lesions $(17,55-60)$. They are degenerative lesions believed to originate from chronic, partial obstruction of submucosal veins with subsequent capillary dilation and damage to capillary sphincters, ultimately resulting in incompetence and finally arteriovenous connections $(17,61)$. This theory fits clinically because most angiodysplastic lesions are found in the cecum, which, due to its larger relative diameter, must exhibit greater wall tension (Laplace's Law) (3,62-64). Approximately $70 \%$ of symptomatic angiodysplastic lesions occur in the right colon $(33 \%$ in the cecum, $39 \%$ in the hepatic flexure or ascending colon), with the sigmoid $(22 \%)$ and transverse colon $(6 \%)$ being affected less frequently $(33,65)$.

Most (70\%) colonic AVMs present with chronic, slow, intermittent and recurrent bleeding rather than hematochezia $(25,66)$. Their importance in patients with massive LGI bleeding varies depending on the study reviewed. Although AVMs are responsible for only $2 \%$ of all LGI bleeding, they account for up to $30 \%$ of all episodes of massive LGI bleeding $(3,22,25-32)$. Most of these lesions are less than $5 \mathrm{~mm}$ in diameter, with only $2 \%$ being larger than $20 \mathrm{~mm}(24,33)$. Their small size may contribute to the difficulty in establishing a diagnosis. Indeed, many patients experience three to five episodes of bleeding before the diagnosis is made (67-69). Associated heart disease, most commonly aortic stenosis, is found in about $50 \%$ of patients (24). This association has been explored by several investigators, but the relationship between aortic stenosis and angiodysplastic lesions remains unclear (56,70-72). Both disorders are known to occur with increasing age; thus, age alone may account for the apparent increased incidence of angiodysplasia in these patients $(3,27)$. Others have postulated that, although there is not a true increased incidence of angiodysplastic lesions in patients with aortic stenosis, the lesions that are present may simply have an increased propensity to bleed. This theory stems from the postulate that aortic stenosis causes a low perfusion state that leads to "ischemic necrosis of the single layer of endothelium which often separates ectatic vessels from the colonic lumen", resulting in LGI hemorrhage (73). Other disease associations with angiodysplasia include cirrhosis, chronic renal failure, prior abdominal radiation therapy and collagen vascular disease.

Endoscopic therapy, once reserved for high risk patients, is now considered to be standard practice for these lesions. Once the lesion has been identified, endoscopic therapy may involve heater probe, bipolar and monopolar electrode, argon plasma coagulation and laser (74). Several studies evaluating endoscopic electrocoagulation have found success rates ranging from $70 \%$ to $80 \%(33,50,56)$. The largest series evaluated was from the Center for Ulcer Research and Education (CURE) Hemostasis Research Group, which enrolled 100 patients with bleeding from colonic angiomata in a long term prospective study over two years. The mean number of colonoscopic treatments was 1.4 (range one to four), with endoscopic coagulation (bipolar or heater probe) performed on 716 colonic angiomas (mean seven per session, range one to 48). When comparing endoscopic treatment with medical treatment (the two years before endoscopic diagnosis), significant decreases were seen in the number of LGI bleeding episodes per year (1.3/year compared with 0.6/year) and number of units of red blood cell transfusions (4.3/year compared with $1.3 /$ year). Similarly, there was significant improvement in hematocrit, which rose from $26.8 \%$ before colonoscopic therapy to $37.3 \%$ after therapy. During long term follow-up, $18 \%$ of patients required surgical intervention (usually a right hemicolectomy); 39\% of these patients continued to have recurrent bleeding after their surgeries. Interestingly, this included four patients with renal failure and one who was taking anticoagulants for cardiac valvular disease (33). Earlier studies on angiodysplastic lesions did not demonstrate such a high recurrent bleeding rate postoperatively, although some patients did have coagulation defects (75).

Complication rates of endoscopic therapy of angiodysplastic lesions range from $4 \%$ to $7 \%$, with more complications occurring in patients who undergo heater probe treatment (7\%), as opposed to bipolar electrocoagulation $(4 \%)$. Cecal lesions may have a slightly increased rate of complications secondary to decreased wall thickness that makes it more susceptible to perforation. Delayed rebleeding appears to be more common in patients with abnormal platelet function and those with giant angiomata. These patients often require surgical intervention (33).

For patients with recurrent bleeding who have lesions that are difficult to treat, are too numerous to be treated with endoscopic therapy or that are presumed to be located within the small intestine, adjunctive therapy with estrogens is suggested. By improving the vascular endothelium and possibly having a primary benefit on coagulation, oral estrogens have been shown to decrease bleeding in select patients, such as those with hereditary hemorrhagic telangiectasia or chronic renal failure (76). 
'Blind hemicolectomy' is rarely indicated in LGI bleeding. The mortality rate associated with surgical resection ranges from $10 \%$ to $50 \%(2,17,56,75)$. This higher risk results from patients who tend to be elderly with multiple coexisting medical problems, including coronary artery disease. Because involvement of small bowel or bilateral colonic angiodysplastic lesions is common, accurate identification of the bleeding site is critical when surgical intervention is being considered $(50,75)$.

Neoplasms: Occult rectal bleeding and the passage of bright red blood per rectum are typical presentations of adenomatous polyps and adenocarcinomas of the colon and rectum. Severe hematochezia, however, is relatively uncommon. Conflicting reports of incidence likely result from referral bias. Rossini et al (28) reported that 32\% of patients with massive colonic bleeding had ulcerated carcinomas or polyps, while Jensen and Machicado (33) reported it as a cause in only $11 \%$ of patients. The true incidence is likely somewhere in between $(4,7,16,20,25,27,63,77)$. Polyps and small cancers are amenable to endoscopic therapy, but most cancers require surgical intervention.

Bleeding is the most common complication after colonoscopic polypectomy. Immediate bleeding (often easily controlled at the time of endoscopy) occurs in up to $3 \%$ of cases $(78,79)$, delayed polypectomy hemorrhage occurs in up to $0.3 \%(1,80-83)$. Treatment of early and late postpolypectomy bleeding is usually endoscopic, with identification of the bleeding stalk being of paramount importance. Grasping the stalk with a snare and recauterizing or simply closing the snare around the stalk for a period of time is usually sufficient to allow a coagulum to form. Other methods of therapy include cauterization and, for patients in whom endoscopic therapy fails, angiographic embolization and surgical resection have been successfully reported (82). If the bleeding appears to be coming from an induced ulcer postpolypectomy, treatment would include injection of adrenaline and the use of the heater or bipolar probe. Lower power settings and light tamponade are recommended. Neodymium:yttrium-aluminum-garnet laser and monopolar electrocoagulation are not recommended in the treatment of these ulcerations because of the possibility of transmural injury (33). In the case of delayed hemorrhage, other sites of bleeding must always be considered preoperatively. If there is any doubt regarding the site of bleeding, a complete colonoscopy must be performed.

Inflammatory bowel disease: Despite that ulcerative colitis and Crohn's disease are characterized by bleeding and diarrhea, massive hematochezia is uncommon, occurring in only $3 \%$ to $5 \%$ of all patients with massive LGI bleeding $(16,20,84,85)$. Up to $6 \%$ of patients with Crohn's disease or ulcerative colitis experience severe LGI bleeding $(86,87)$. The incidence may be slightly higher in Crohn's disease, secondary to the transmural nature of the disorder (21). In Crohn's disease, the distribution of bleeding reflects the frequency with which an area of the bowel is affected, with the ileum being the most commonly affected. Most patients with Crohn's disease who present with massive hema- tochezia are known to have had Crohn's disease for at least several years (88). Medical therapy is usually the initial treatment choice because therapy for the underlying disorder may result in control of hemorrhage. Unfortunately, although $50 \%$ of patients stop bleeding spontaneously, 35\% will rebleed; thus, an urgent colectomy is recommended for patients with colitis who suffer a life-threatening hemorrhage $(1,33,86,87)$. Proctectomy is reserved for patients in whom the rectum is the primary site of bleeding. In ulcerative colitis, colectomy and end ileostomy with preservation of the rectal stump (to allow elective proctectomy and construction of an ileoanal reservoir at a later date) are recommended methods of resection; in Crohn's colitis, colectomy with ileoproctostomy (provided that the rectum is not inflamed or not the site of bleeding) is recommended $(21,89)$.

Focal ulceration: Focal ulceration with severe hemorrhage is a rare cause of massive LGI bleeding. This ulceration may arise from inflammatory bowel disease or after polypectomy, as discussed above, or from infection or ischemia.

Typical infections include cytomegalovirus (in immunocompromised patients) and pseudomembranous colitis. These infections are often first suspected at clinical presentation because both are usually accompanied by diarrhea, and are associated with either immune suppression or recent antibiotic exposure. Other infections, such as amebiasis, have occasionally been reported to cause severe gastrointestinal hemorrhage (90). Treatment is directed at the underlying cause of the bleeding, not necessarily at the bleeding itself. If endoscopic therapy is attempted, it should be performed only after failure of medical treatment. These bleeding lesions can be treated with a combination of adrenaline injection with or without the use of bipolar probe. Extreme caution must be employed because the colonic wall of these lesions is typically thin and easily perforated. Some patients require colectomy for definitive therapy. Cold guillotining-off of adherent clots, as performed in UGI ulcers, has been suggested by Jensen and Machicado (33) for focal colonic ulcers with adherent clots.

Although bloody diarrhea is common with ischemic colitis, significant LGI hemorrhage is unusual $(21,91,92)$. Different types of ischemic episodes must be considered. Acute occlusive ischemic mesenteric episodes usually present as pain and, therefore, are seldom confused with other more common causes of LGI hemorrhage. Presentation is sudden and severe; the patient often has a history of cardiac disease. Nonocclusive types of acute ischemia present with vague and nonspecific symptoms but rarely significant LGI hemorrhage. Early angiography and surgical intervention improve the opportunity for intestinal salvage $(3,17,19$, $82,93)$. Chronic ischemia involving the small bowel may present with diarrhea secondary to malabsorption, but because only $5 \%$ of patients with colonic ischemia experience recurrent episodes, chronic colonic ischemia is rare (82).

The use of nonsteroidal anti-inflammatory drugs (NSAIDs) has been shown to result in significant morbid- 
ity from deleterious effects on the UGI tract, but their effect on the LGI tract is often forgotten. Profuse diarrhea, chronic blood loss, iron deficiency anemia and increased risk of bleeding from diseased regions (eg, diverticula) have all been attributed to NSAID use $(25,94,95)$. NSAIDs may increase the risk of bleeding in patients with known abnormalities within the colon through platelet inhibition. Patients with any history of gastrointestinal hemorrhage, including colonic, should be cautioned regarding the use of these drugs.

Anorectal disease: Although hemorrhoids are the most common source of LGI bleeding $(21,25,92,93,95)$, massive ongoing bleeding is distinctly unusual. Recurrent bleeding can occasionally lead to iron deficiency with subsequent microcytic anemia (96). Rarely, hemorrhoids may bleed profusely and require urgent surgical intervention. It is imperative to rule out perianal bleeding before pursuing other more complex and invasive investigations for LGI hemorrhage. This is usually satisfactorily done with a rectal examination combined with either proctoscopy or sigmoidoscopy.

Anorectal, colonic and peristomal varices can cause severe, painless massive LGI hemorrhage. Although usually caused by cirrhosis complicated by portal hypertension, they can also result from severe congestive heart failure, portal vein thrombosis and congenital abnormalities of the mesenteric venous system $(97,98)$. Anorectal varices may

\section{REFERENCES}

1. Billingham RP. The conundrum of lower gastrointestinal bleeding. Surg Clin North Am 1997;77:241-51.

2. Drapanas T, Pennington DG, Kappelman M, Lindsey ES. Emergency subtotal colectomy: preferred approach to management of massively bleeding diverticular disease. Ann Surg 1973;177:519-26.

3. Boley SJ, DiBiase A, Brandt LJ, Sammartano RJ. Lower intestinal bleeding in the elderly. Am J Surg 1979;137:57-64.

4. Caos A, Benner KG, Manier J, et al. Colonoscopy after Golytely preparation in acute rectal bleeding. J Clin Gastroenterol 1986;8:46-9.

5. McGuire HH Jr, Haynes BW Jr. Massive hemorrhage for diverticulosis of the colon: guidelines for therapy based on bleeding patterns observed in fifty cases. Ann Surg 1972;175:847-55.

6. Hunter JM, Pezim ME. Limited value of technetium $99 \mathrm{~m}$-labeled red cell scintigraphy in localization of lower gastrointestinal bleeding. Am J Surg 1990;159:504-6.

7. Lewis BS, Kornbluth A, Waye JD. Small bowel tumours: yield of enteroscopy. Gut 1991;32:763-5.

8. The role of endoscopy in the patient with lower gastrointestinal bleeding. Guidelines for clinical application. Gastrointest Endosc 1988;34:23S-5S.

9. Zuccaro G Jr. Management of the adult patient with acute lower gastrointestinal bleeding. Am J Gastroenterol 1998;93:1202-8.

10. Zuckerman GR, Prakash C. Acute lower intestinal bleeding. Part II: etiology, therapy, and outcomes. Gastrointest Endosc 1999;49:228-38.

11. Zuckerman GR, Prakash C. Acute lower intestinal bleeding: Part I: clinical presentation and diagnosis. Gastrointest Endosc 1998;48:606-17.

12. Greenburg AG, Saik RP, Bell RH, Collins GM. Changing patterns of gastrointestinal bleeding. Arch Surg 1985;120:341-4.

13. Steer ML, Silen W. Diagnostic procedures in gastrointestinal hemorrhage. N Engl J Med 1983;309:646-50.

14. Blackstone MO, Kirsner JB. Establishing the site of gastrointestinal bleeding. JAMA 1979;241:599.

15. Dorland WAN, ed. Dorland's Illustrated Medical Dictionary, 26 edn. Philadelphia: Saunders, 1985.

16. Ryan P, Styles CB, Chmiel R. Identification of the site of severe colon bleeding by technetium-labeled red-cell scan. Dis Colon Rectum 1992;35:219-22. be present in up to $89 \%$ of patients with portal hypertension. They are best diagnosed endoscopically. Definitive treatment may require portal decompression (surgical or transjugular) or, in appropriate patients, liver transplantation. Bleeding from anorectal and peristomal varices can often be controlled with injection sclerotherapy. There may also be a role for endoscopic banding. Colectomy for bleeding varices is associated with high mortality $(90 \%)$ and should be avoided (97,99-103).

Other sources of gastrointestinal hemorrhage: The UGI tract should always be considered in patients presenting with bright red blood per rectum. Approximately 10\% to $15 \%$ of cases of acute rectal bleeding have a UGI source (104). If an upper endoscopy and an evaluation of the colon are both negative, the small bowel should also be considered as a possible source of bleeding. It is responsible for 3\% to $5 \%$ of LGI bleeding episodes $(27,77,105,106)$. Specific diagnosis and localization are often difficult because of the small bowel length, redundancy, tortuosity and general inaccessibility. Angiodysplasia accounts for $70 \%$ to $80 \%$ of small bowel hemorrhage with other diagnoses, including jejunoileal diverticula $(105,107)$, Meckel's diverticulum (63), neoplasia (benign and malignant), enteritis and aortoenteric fistula $(56,89,105,108)$.

ACKNOWLEDGEMENT: The author thanks DR Alan Barkun for assistance in the preparation of this manuscript.

17. Boley SJ, Sammartano R, Adams A, DiBiase A, Kleinhaus S, Sprayregen S. On the nature and etiology of vascular ectasias of the colon. Degenerative lesions of aging. Gastroenterology 1977;72:650-60.

18. Berner JS, Mauer K, Lewis BS. Push and sonde enteroscopy for the diagnosis of obscure gastrointestinal bleeding. Am J Gastroenterol 1994;89:2139-42.

19. Howard TJ, Plaskon LA, Wiebke EA, Wilcox MG, Madura JA. Nonocclusive mesenteric ischemia remains a diagnostic dilemma. Am J Surg 1996;171:405-8.

20. Milewski PJ, Schofield PF. Massive colonic haemorrhage the case for right hemicolectomy. Ann R Coll Surg Engl 1989;71:253-9.

21. Vernava AM, Moore BA, Longo WE, Johnson FE. Lower gastrointestinal bleeding. Dis Colon Rectum 1997;40:846-58

22. Vernava AM, Longo WE, Virgo KS, Johnson FE. A nationwide study of the incidence and etiology of lower gastrointestinal bleeding. Surg Res Commun 1996;18:113-20.

23. Murray J. Lower gastrointestinal bleeding. In: Mazier WP, Levien DH, Luchtefeld MA, Senagore AJ, eds. Surgery of the Colon, Rectum, and Anus. Philadephia: WB Saunders, 1994:763-73.

24. Rosen AM, Fleischer DE. Upper GI bleeding in the elderly: diagnosis and management. Geriatrics 1933;44:26-28.

25. Jensen DM, Machicado GA. Diagnosis and treatment of severe hematochezia. The role of urgent colonoscopy after purge. Gastroenterology 1988;95:1569-74.

26. Heer M, Ammann R, Buhler H. [Clinical significance of colonic angiodysplasias]. Schweiz Med Wochenschr 1984;114:1416-22.

27. Leitman IM, Paull DE, Shires GT. Evaluation and management of massive lower gastrointestinal hemorrhage. Ann Surg 1989;209:175-80.

28. Rossini FP, Ferrari A, Spandre M, et al. Emergency colonoscopy. World J Surg 1989;13:190-2.

29. Wright HK. Massive colonic hemorrhage. Surg Clin North Am 1980;60:1297-304.

30. Baum S, Athanasoulis CA, Waltman AC. Angiographic diagnosis and control of large-bowel bleeding. Dis Colon Rectum 1974;17:447-53. 
31. Colacchio TA, Forde KA, Patsos TJ, Nunez D. Impact of modern diagnostic methods on the management of active rectal bleeding. Ten year experience. Am J Surg 1982;143:607-10.

32. Forde KA. Colonoscopy in acute rectal bleeding. Gastrointest Endosc 1981;27:219-20.

33. Jensen DM, Machicado GA. Colonoscopy for diagnosis and treatment of severe lower gastrointestinal bleeding. Routine outcomes and cost analysis. Gastrointest Endosc Clin North Am 1997;7:477-98.

34. Hughes LE. Postmortem survey of diverticular disease of the colon. I. Diverticulosis and diverticulitis. Gut 1969;10:336-44.

35. Gennaro AR, Rosemond GP. Pathogenesis of diverticulosis of the colon. Dis Colon Rectum 1974;17:64-73.

36. Bokhari M, Vernava AM, Ure T, Longo WE. Diverticular hemorrhage in the elderly - is it well tolerated? Dis Colon Rectum 1996;39:191-5.

37. Gennaro AR, Rosemond GP. Colonic diverticula and hemorrhage. Dis Colon Rectum 1973;16:409-15.

38. Healey SJ, Pfeffer RI. Exsanguinating hemorrhage from diverticulosis of the ascending colon. Report of a case. N Engl J Med 1965;273:1480-1.

39. Klein RR, Gallagher DM. Massive colonic bleeding from diverticular disease. Am J Surg 1969;118:553-7.

40. Meyers MA, Alonso DR, Gray GF, Baer JW. Pathogenesis of bleeding colonic diverticulosis. Gastroenterology 1976;71:577-83.

41. Savides TJ, Jensen DM. Colonoscopic hemostasis for recurrent diverticular hemorrhage associated with a visible vessel: a report of three cases. Gastrointest Endosc 1994;40:70-3.

42. Szold A, Katz LB, Lewis BS. Surgical approach to occult gastrointestinal bleeding. Am J Surg 1992;163:90-2.

43. Mauldin JL. Therapeutic use of colonoscopy in active diverticular bleeding. Gastrointest Endosc 1985;31:290-1. (Lett)

44. Kim YI, Marcon NE. Injection therapy for colonic diverticular bleeding. A case study. J Clin Gastroenterol 1993;17:46-8.

45. Singh BM, Gostout CJ. Endoscopic hemiclip treatment for gastrointestinal bleeding. Gastrointest Endosc 1994;40:127-8.

46. Binmoeller KF, Thonke F, Soehendra N. Endoscopic hemoclip treatment for gastrointestinal bleeding. Endoscopy 1993;25:167-70.

47. Farrell J, Kelsey P. Endoscopic band ligation of bleeding colonic diverticula: an ex vivo and in vivo study. Gastrointest Endosc 1999;49:AB136. (Abst)

48. Margulis AR, Heinbecker, Bernard H. Operative mesenteric arteriography in the search for the site of bleeding in unexplained gastrointestinal hemorrhage; a preliminary report. Surgery 1960;48:534-9.

49. Baum S, Nusbaum, Karoda K, Blakemore WS. Direct serial magnification arteriography as an adjunct in the diagnosis of surgical lesions of the alimentary tract. Am J Surg 1969;170:170-6.

50. Trudel JL, Fazio VW, Sivak MV. Colonoscopic diagnosis and treatment of arteriovenous malformations in chronic lower gastrointestinal bleeding. Clinical accuracy and efficacy. Dis Colon Rectum 1988;31:107-10.

51. Brand EJ, Sullivan BHJ, Sivak MVJ, Rankin GB. Colonoscopy in the diagnosis of unexplained rectal bleeding. Ann Surg 1980;192:111-3.

52. Brandt LJ, Boley SJ. The role of colonoscopy in the diagnosis and management of lower intestinal bleeding. Scand J Gastroenterol Suppl 1984;102:61-70.

53. Hagihara PF, Chuang VP, Griffen WO. Arteriovenous malformations of the colon. Am J Surg 1977;133:681-7.

54. Fowler DL, Fortin D, Wood WG, Pinkerton JAJ, Koontz PG Jr. Intestinal vascular malformations. Surgery 1979;86:377-85.

55. Danesh BJ, Spiliadis C, Williams CB, Zambartas CM. Angiodysplasia an uncommon cause of colonic bleeding: colonoscopic evaluation of 1,050 patients with rectal bleeding and anaemia. Int J Colorectal Dis 1987;2:218-22.

56. Gupta N, Longo WE, Vernava AM. Angiodysplasia of the lower gastrointestinal tract: an entity readily diagnosed by colonoscopy and primarily managed nonoperatively. Dis Colon Rectum 1995;38:979-82

57. Heer M, Sulser H, Hany A. Angiodysplasia of the colon: an expression of occlusive vascular disease. Hepatogastroenterology 1987;34:127-31.

58. Hochter W, Weingart J, Kuhner W, Frimberger E, Ottenjann R. Angiodysplasia in the colon and rectum. Endoscopic morphology, localisation and frequency. Endoscopy 1985;17:182-5.
59. Richter JM, Hedberg SE, Athanasoulis CA, Schapiro RH. Angiodysplasia. Clinical presentation and colonoscopic diagnosis. Dig Dis Sci 1984;29:481-5.

60. Zuckerman G, Benitez J. A prospective study of bidirectional endoscopy (colonoscopy and upper endoscopy) in the evaluation of patients with occult gastrointestinal bleeding. Am J Gastroenterol 1992;87:62-6.

61. Mitsudo SM, Boley SJ, Brandt LJ, Montefusco CM, Sammartano RJ. Vascular ectasias of the right colon in the elderly: a distinct pathologic entity. Hum Pathol 1979;10:585-600.

62. Boley SJ, Brandt LJ, Frank MS. Severe lower intestinal bleeding: diagnosis and treatment. Clin Gastroenterol 1981;10:65-91.

63. Ellis DJ, Reinus JF. Lower intestinal hemorrhage. Crit Care Clin 1995;11:369-89.

64. Reinus JF, Brandt LJ. Vascular ectasias and diverticulosis. Common causes of lower intestinal bleeding. Gastroenterol Clin North Am 1994:23:1-20.

65. Unger SW, Saranto JR, Furlong RJ, Scott JS. Single session panendoscopy. Indications and expectations for yield. Am Surg 1990;56:144-7.

66. Jensen DM, Machicado GA. Endoscopic diagnosis and treatment of bleeding colonic angiomas and radiation telangiectasias. Perspect Colon Rectal Surg 1989;2:99-113.

67. Holt S, Rigoglioso V, Sidhu M, Irshad M, Howden CW, Mainero M. Nonsteroidal antiinflammatory drugs and lower gastrointestinal bleeding. Dig Dis Sci 1993;38:1619-23.

68. Foutch PG, Sawyer R, Sanowski RA. Push-enteroscopy for diagnosis of patients with gastrointestinal bleeding of obscure origin. Gastrointest Endosc 1990;36:337-41.

69. Britt LG, Warren L, Moore OF. Selective management of lower gastrointestinal bleeding. Am Surg 1983;49:121-5.

70. Weaver GA, Alpern HD, Davis JS, Ramsey WH, Reichelderfer M. Gastrointestinal angiodysplasia associated with aortic valve disease: part of a spectrum of angiodysplasia of the gut. Gastroenterology 1979;77:1-11.

71. Imperiale TF, Ransohoff DF. Aortic stenosis, idiopathic gastrointestinal bleeding, and angiodysplasia: is there an association? A methodologic critique of the literature. Gastroenterology 1988;95:1670-6.

72. Bowden TAJ, Hooks VH, Mansberger AR Jr. Intestinal vascular ectasias: a new look at an old disease. South Med J 1982;75:1310-7.

73. Boley SJ, Brandt LJ. Vascular ectasias of the colon - 1986. Dig Dis Sci 1986;31:26S-42S.

74. Cello JP, Grendell JH. Endoscopic laser treatment for gastrointestinal vascular ectasias. Ann Intern Med 1986;104:352-4.

75. Smith GF, Ellyson JH, Parks SN, et al. Angiodysplasia of the colon. A review of 17 cases. Arch Surg 1984;119:532-6.

76. Bronner MH, Pate MB, Cunningham JT, Marsh WH. Estrogenprogesterone therapy for bleeding gastrointestinal telangiectasias in chronic renal failure. An uncontrolled trial. Ann Intern Med 1986;105:371-4.

77. Kouraklis G, Misiakos E, Karatzas G, Gogas J, Skalkeas G. Diagnostic approach and management of active lower gastrointestinal hemorrhage. Int Surg 1995;80:138-40.

78. Fruhmorgen P, Demling L. Complications of diagnostic and therapeutic colonoscopy in the Federal Republic of Germany. Results of an inquiry. Endoscopy 1979;11:146-50.

79. Geenen JE, Schmitt MG Jr, Wu WC, Hogan WJ. Major complications of coloscopy: bleeding and perforation. Am J Dig Dis 1975;20:231-5.

80. Habr-Gama A, Waye JD. Complications and hazards of gastrointestinal endoscopy. World J Surg 1989;13:193-201.

81. Jentschura D, Raute M, Winter J, Henkel T, Kraus M, Manegold BC. Complications in endoscopy of the lower gastrointestinal tract. Therapy and prognosis. Surg Endosc 1994;8:672-6.

82. Rosen L, Bub DS, Reed JF, Nastasee SA. Hemorrhage following colonoscopic polypectomy. Dis Colon Rectum 1993;36:1126-31.

83. Waye JD, Lewis BS, Yessayan S. Colonoscopy: a prospective report of complications. J Clin Gastroenterol 1992;15:347-51.

84. Setya V, Singer JA, Minken SL. Subtotal colectomy as a last resort for unrelenting, unlocalized, lower gastrointestinal hemorrhage: experience with 12 cases. Am Surg 1992;58:295-9.

85. Stoney RJ, Cunningham CG. Acute mesenteric ischemia. Surgery 1993;114:489-90.

86. Robert JH, Sachar DB, Aufses AH Jr, Greenstein AJ. Management of severe hemorrhage in ulcerative colitis. Am J Surg 1990;159:550-5. 
87. Robert JR, Sachar DB, Greenstein AJ. Severe gastrointestinal hemorrhage in Crohn's disease. Ann Surg 1991;213:207-11.

88. Cirocco WC, Reilly JC, Rusin LC. Life-threatening hemorrhage and exsanguination from Crohn's disease. Report of four cases. Dis Colon Rectum 1995;38:85-95.

89. Buchman TG, Bulkley GB. Current management of patients with lower gastrointestinal bleeding. Surg Clin North Am 1987;67:651-64.

90. Eggleston FC, Verghese M, Handa AK. Amebiasis causing massive gastrointestinal bleeding. Arch Surg 1978;113:1472.

91. Gandhi SK, Hanson MM, Vernava AM, Kaminski DL, Longo WE. Ischemic colitis. Dis Colon Rectum 1996;39:88-100.

92. Shinya H, Cwern M, Wolf G. Colonoscopic diagnosis and management of rectal bleeding. Surg Clin North Am 1982;62:897-903.

93. Jensen DM, Machicado GA. Management of severe gastrointestinal bleeding. In: Barkin JS, Odurny A, eds. Advanced Therapeutic Endoscopy, 2nd edn. New York: Raven Press, 1994:201-8.

94. Allison MC, Howatson AG, Torrance CJ, Lee FD, Russell RI. Gastrointestinal damage associated with the use of nonsteroidal antiinflammatory drugs. N Engl J Med 1992;327:749-54.

95. Makela JT, Kiviniemi H, Laitinen S, Kairaluoma MI. Diagnosis and treatment of acute lower gastrointestinal bleeding. Scand J Gastroenterol 1993;28:1062-6.

96. Randall GM, Jensen DM, Machicado GA, et al. Prospective randomized comparative study of bipolar versus direct current electrocoagulation for treatment of bleeding internal hemorrhoids. Gastrointest Endosc 1994;40:403-10.

97. Cappell MS, Price JB. Characterization of the syndrome of small and large intestinal variceal bleeding. Dig Dis Sci 1987;32:422-7.

98. Strong SA. Colonic, anorectal and peristomal varices. Semin Colon Rectal Surg 1994;5:50-8.

99. Lichtiger S, Karnbluth A, Salomon P, et al. Lower gastrointestinal bleeding. In: Taylor MB, Gollan JL, Peppercorn MA, et al, eds. Gastrointestinal Emergencies, 1st edn. Baltimore: Williams \& Wilkins, 1992:358.

100. Chawla Y, Dilawari JB. Anorectal varices - their frequency in cirrhotic and non-cirrhotic portal hypertension. Gut 1991;32:309-11.

101. Goenka MK, Kochhar R, Nagi B, Mehta SK. Rectosigmoid varices and other mucosal changes in patients with portal hypertension. Am J Gastroenterol 1991;86:1185-9.

102. Hosking SW, Smart HL, Johnson AG, Triger DR. Anorectal varices, haemorrhoids, and portal hypertension. Lancet 1989;i:349-52.

103. Katz LB, Shakeed A, Messer J. Colonic variceal hemorrhage: diagnosis and management. J Clin Gastroenterol 1985;7:67-9.

104. Levinson SL, Powell DW, Callahan WT, et al. A current approach to rectal bleeding. J Clin Gastroenterol 1981;3(Suppl 1):9-16.

105. Gilmore PR. Angiodysplasia of the upper gastrointestinal tract. J Clin Gastroenterol 1988;10:386-94.

106. Netterville RE, Hardy JD, Martin RS Jr. Small bowel hemorrhage. Ann Surg 1968;167:949-57.

107. Longo WE, Vernava AM. Clinical implications of jejunoileal diverticular disease. Dis Colon Rectum 1992;35:381-8.

108. Morris AJ, Wasson LA, MacKenzie JF. Small bowel enteroscopy in undiagnosed gastrointestinal blood loss. Gut 1992;33:887-9. 


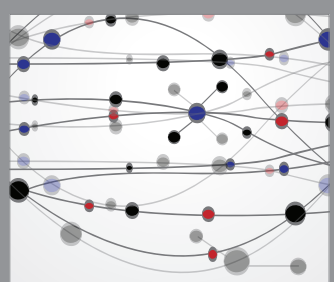

The Scientific World Journal
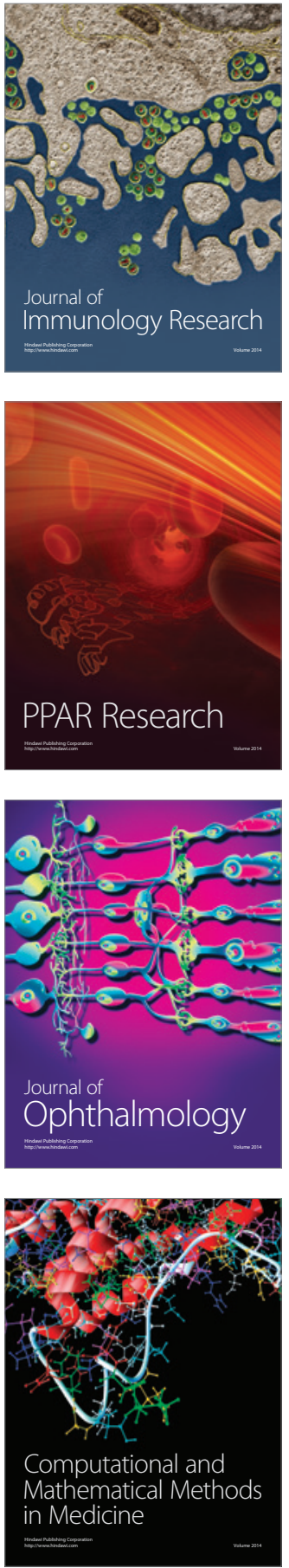

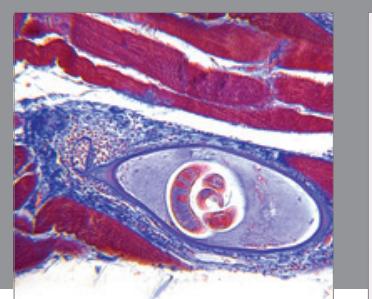

Gastroenterology Research and Practice

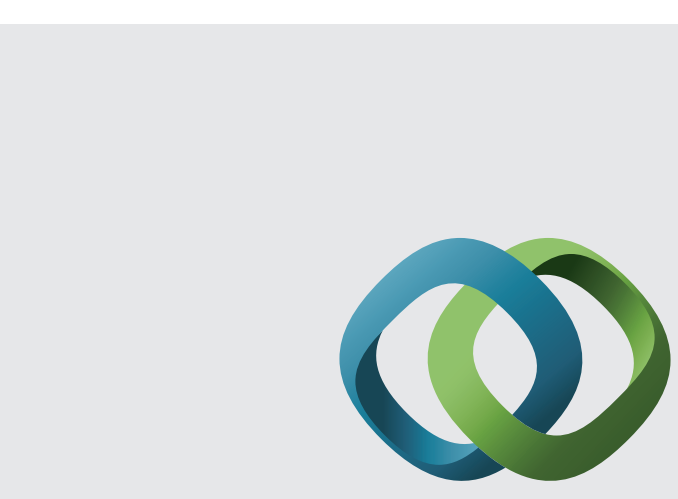

\section{Hindawi}

Submit your manuscripts at

http://www.hindawi.com
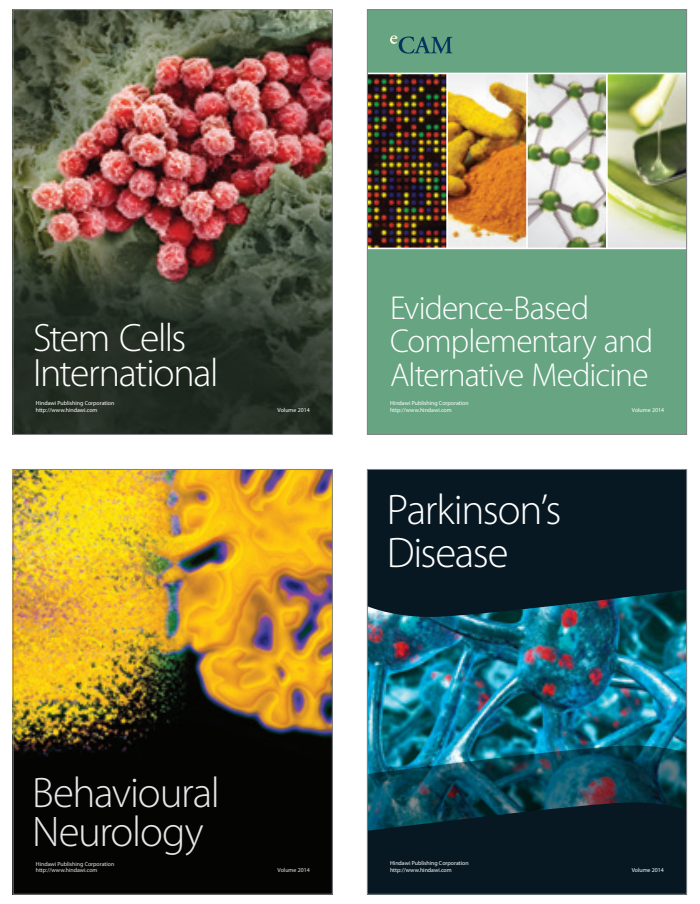
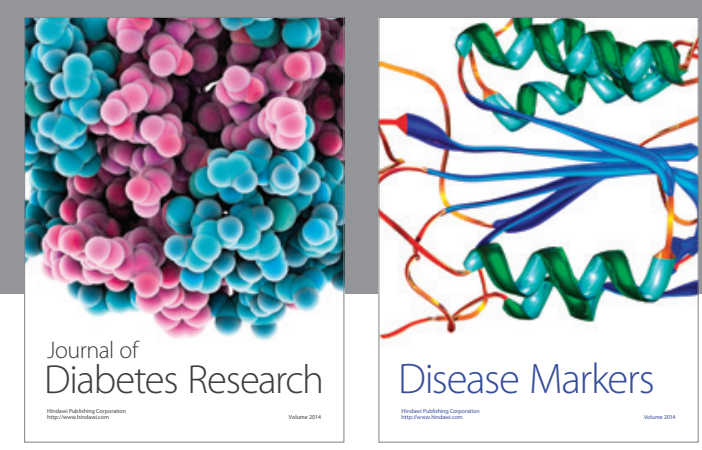

Disease Markers
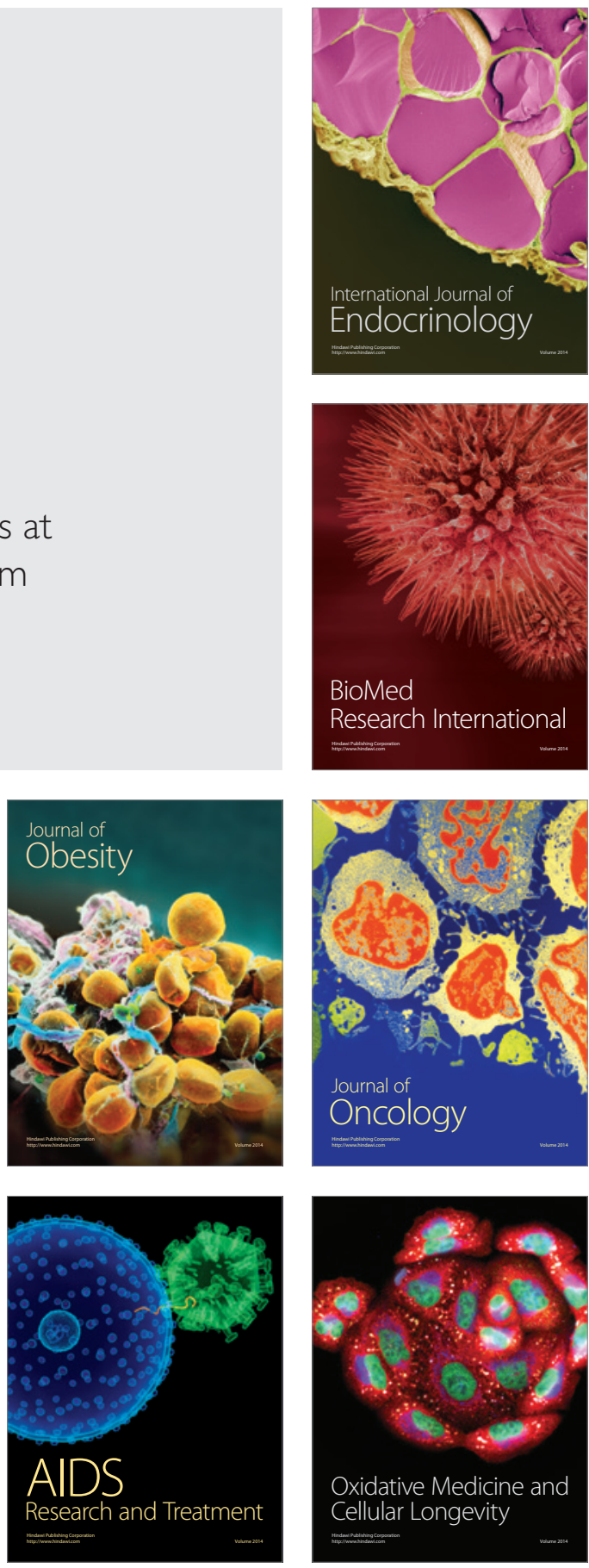